\title{
Tribocorrosion behavior of bio-functionalized highly porous titanium
}

\author{
F. Toptan ${ }^{\mathrm{a}, \mathrm{b}, *}$, A.C. Alves $^{\mathrm{a}}$, A.M.P. Pinto ${ }^{\mathrm{a}, \mathrm{b}}$, P. Ponthiaux ${ }^{\mathrm{c}}$ \\ a CMEMS-UMinho - Center for MicroElectroMechanical Systems - Universidade do Minho, Azurém, 4800-058 Guimarães, Portugal \\ ${ }^{\mathrm{b}}$ Universidade do Minho, Dept. Eng. Mecânica, Azurém, 4800-058 Guimarães, Portugal \\ c Laboratoire de Génie des Procédés et Matériaux-LGPM, École Centrale de Paris, Grande Voie des Vignes, 92290 Chatenây-Malabry, France
}

\section{A R T I C L E I N F O}

Keywords:

Anodic treatment

Powder metallurgy

Porous Ti

Tribocorrosion

\begin{abstract}
A B S T R A C T
Titanium and its alloys are widely used in orthopedic and dental implants, however, some major clinical concerns such as poor wear resistance, lack of bioactivity, and bone resorption due to stress shielding are yet to be overcome. In order to improve these drawbacks, highly porous Ti samples having functionalized surfaces were developed by powder metallurgy with space holder technique followed by anodic treatment. Tribocorrosion tests were performed in $9 \mathrm{~g} / \mathrm{L} \mathrm{NaCl}$ solution using a unidirectional pin-on-disc tribometer under $3 \mathrm{~N}$ normal load, $1 \mathrm{~Hz}$ frequency and $4 \mathrm{~mm}$ track diameter. Open circuit potential (OCP) was measured before, during and after sliding. Worn surfaces investigated by field emission gun scanning electron microscope (FEG-SEM) equipped with energy dispersive X-ray spectroscopy (EDS). Results suggested bio-functionalized highly porous samples presented lower tendency to corrosion under sliding against zirconia pin, mainly due to the load carrying effect given by the hard protruded oxide surfaces formed by the anodic treatment.
\end{abstract}

\section{Introduction}

Titanium and its alloys are widely used in orthopedic and dental implants due to their excellent corrosion resistance, high yield strength, good ductility and better biocompatibility (Chen et al., 2009; Guo et al., 2013). However, some major clinical concerns are still valid, namely bone resorption due to stress shielding, lack of bioactivity, and low wear resistance.

Most commercially used Ti-based implant materials exhibit much higher Young's modulus (Commercially pure Ti: $105 \mathrm{GPa}$, Ti-6Al-4V: $110 \mathrm{GPa}$ ) as compared to human bones (varies in a range of 4-30 $\mathrm{GPa}$ ) (Guo et al., 2013; De Viteri and Fuentes, 2013; Nag and Banerjee, 2012). Studies have shown that implants do not adequately strain the bone that can result in disuse atrophy and bone resorption due to the difference on Young's modulus between implant and bone. This phenomenon known as stress shielding that is one of the major cause of orthopedic implant failures by resulting in bone resorption (Lee et al., 2012).

In order to avoid stress shielding, on one hand, $\beta$ and near $\beta$ alloys with lower Young's modulus such as Ti-Nb-Ta-Zr, Ti-Nb-Si, Ti-Mo-Nb, Ti-Zr-Mo are being developed (Guo et al., 2013; Martins and Grandini, 2014; Correa et al., 2014), but on the other hand, porous Ti implants having open-cellular structure are also being developed not just to reduce the biomechanical mismatch, but as well for the possibilities of the new-bone tissue in-growth, or even the transport of the body fluids and their potential use on drug delivery systems (Goriainov et al., 2014; Amin Yavari et al., 2014; Lee et al., 2014; Jha et al., 2013).

$\mathrm{Ti}$ is the most biocompatible metallic material, however, it cannot create a direct bond with bone to promote new bone formation at the early stage after implantation, which is required for the rapid fixation of bone to implant. This leads to the early implant failure particularly for the patient groups with the diseases such as diabetes, osteoporosis, and chronic inflammation (Gosavi et al., 2013; Tanigawa et al., 2013; Hu et al., 2011).

When an implant material attached to the bone, during the cyclic loads, relative movements cause wear (Thomann and Uggowitzer, 2000; Ganesh et al., 2012). Furthermore, implants are surrounded by corrosive body fluids, thus they suffer not only wear, but the simultaneous action of corrosion and wear that is defined as tribocorrosion, being an irreversible process that occurs on the surface causing the deterioration of the material (Marino and Mascaro, 2004; Landolt et al., 2004). It is known that under this simultaneous action, total material loss may be significantly higher than that of the mechanical wear or corrosion, individually (Mischler, 2008).

In addition to hard coatings, surface modifications are also being applied in order to improve the wear resistance of $\mathrm{Ti}(\mathrm{Hu}$ and $\mathrm{Lim}$, 2010; Wood, 2007; Alves et al., 2013). Among these surface modification techniques, anodic treatment not only leads to better corrosion and tribocorrosion resistance through the formation of porous titanium oxide layers, but also improves the interaction of the implant surface

\footnotetext{
* Corresponding author at: Universidade do Minho, Dept. Eng. Mecânica, Azurém, 4800-058 Guimarães, Portugal

E-mail address: ftoptan@dem.uminho.pt (F. Toptan).
} 
with host tissue by tailoring Ti surfaces in terms of topography, porosity, and composition leading to a better osteointegration (Alves et al., 2013; Ishizawa and Ogino, 1995; Szesz et al., 2013; Teixeira et al., 2015; Fazel et al., 2015). The technique also allows to incorporate $\mathrm{Ca}$ and $\mathrm{P}$ with a similar $\mathrm{Ca} / \mathrm{P}$ ratio to hydroxyapatite (HA) which afterwards can be precipitated as crystals by hydrothermal treatment that leads to increase the bioactivity (Benea et al., 2014). There are some studies in the literature showing that it is also possible to modify highly porous Ti surfaces by anodic treatment (Amin Yavari et al., 2014; Teixeira et al., 2015; Fan et al., 2011).

Most of the studies on highly porous $\mathrm{Ti}$ were focused on the mechanical behavior, while there is very limited information on the corrosion or wear behavior. Electrochemical studies showed that porosity can alter the corrosion behavior of materials either by localized corrosion due to the trapping of electrolyte species and the exhaustion of oxygen in the small, isolated pores, or by the differences between the nature and the structure of the oxide film formed on the top surfaces and on the inner pore surfaces (Seah and Chen, 1993; Seah et al., 1998; Li et al., 2002; Menini et al., 2006; Xie et al., 2013; Alves et al., 2016).

The limited number of studies performed on the wear behavior of porous metals showed that porosity can have positive or negative effects on the wear behavior of metallic materials. First of all, pores result with decreased real contact area between the sliding surfaces thus increase the contact pressure on the metallic surface where higher effective stress and higher possibility of crack nucleation and propagation can increase the material degradation (Mondal et al., 2009; Hamid et al., 2008; Jha et al., 2011). However, during sliding, depending on their fraction and size, the pores can be filled up by the wear debris, furthermore, the debris can be compacted in the pores under the influence of the applied load. In this case, the real contact area will be increased, consequently, the contact pressure will be decreased that may result in increased wear resistance (Mondal et al., 2009; Jha et al., 2011). On the other hand, under lubricated conditions such as body conditions where body fluids can act as lubricant, pores can act as reservoirs for the body fluids and as a result, may lower the coefficient of friction and increase the wear resistance (Salahinejad et al., 2010).

Although these first attempts made valuable insights to the corrosion and wear behavior of the highly porous metals, it is clear that further studies are needed in order to have a better understanding on their degradation mechanisms. Moreover, the combined action of corrosion and wear, and their synergistic interactions are also needed to be evaluated. However, to the best of our knowledge, there is no study available in the literature on the tribocorrosion behavior of these materials. Thus, the present study aimed to be the first insight to the tribocorrosion behavior of as-processed and anodized Ti having closed and open pores.

\section{Materials and methods}

\subsection{Processing}

Highly porous cylindrical Ti samples $12 \mathrm{~mm}$ in diameter and $3 \mathrm{~mm}$ in height were processed by powder metallurgy with space holder technique using angular shaped $\mathrm{Ti}$ powders having average size of $25 \mu \mathrm{m}$ (Grade 2, Alfa Aesar), angular shaped urea space holder particles under $500 \mu \mathrm{m}$ (Scharlau), and PVA as binder (Sigma Aldrich Chemistry).

Titanium, urea (30 and 50 vol\%) and PVA (0.4 vol\%) were mixed using a ball mill rotating with alumina balls at $130 \mathrm{rpm}$ during $4 \mathrm{~h}$. Powder blends were uniaxially pressed in a zinc stearate lubricated nitrided stainless steel die under $350 \mathrm{MPa}$ for $2 \mathrm{~min}$. Green compacts were pre-heated under argon atmosphere at $450{ }^{\circ} \mathrm{C}$ during $3 \mathrm{~h}$ for binder and space holder removal. Afterwards, the samples were heated up to $1100^{\circ} \mathrm{C}$ with $5^{\circ} \mathrm{C} / \mathrm{min}$ heating rate and sintered during $3 \mathrm{~h}$ in horizontal tubular furnace under high vacuum $\left(<10^{-5} \mathrm{mbar}\right)$. The

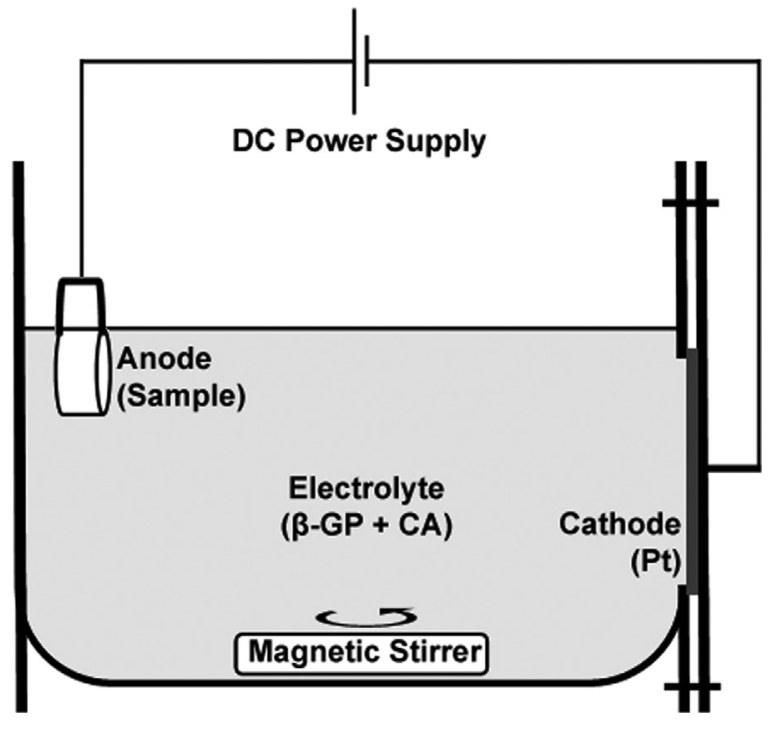

Fig. 1. Schematic representation of the anodic treatment test setup.

binder/space holder removal and sintering temperatures were chosen after differential thermal analysis and thermal gravimetric analysis (DTA/TG), together with dilatometric analysis that had been presented elsewhere (Alves et al., 2016).

\subsection{Anodic treatment}

The functionalization of the dense and porous samples were realized by anodic treatment using an electrolyte containing $0.02 \mathrm{M}$ of $\beta$-glycerophosphate disodium salt pentahydrate $(\beta$-GP; FlukaBioChemika) and $0.35 \mathrm{M}$ of calcium acetate monohydrate (CA; Sigma-Aldrich). This electrolyte was chosen to incorporate bioactive species, namely $\mathrm{P}$ (from $\beta$-GP) and $\mathrm{Ca}$ (from CA). Prior to the treatment, the samples were etched in Kroll's reagent $(2 \mathrm{ml} \mathrm{HF}$, $10 \mathrm{ml} \mathrm{HNO}_{3}, 88 \mathrm{ml} \mathrm{H} \mathrm{H}_{2} \mathrm{O}$ ) for $1 \mathrm{~min}$. The anodic treatment was performed at room temperature using a DC power supply (GPR30H10D) under a constant voltage of $300 \mathrm{~V}$ during $1 \mathrm{~min}$ where all sample (anode) immersed into the electrolyte solution and positioned $8 \mathrm{~cm}$ away from a platinum plate that was used as the cathode with an exposed area of $3.39 \mathrm{~cm}^{2}$. All the anodic treatments were carried out under magnetic stirring at $200 \mathrm{rpm}$ (Fig. 1).

\subsection{Tribocorrosion tests}

Tribocorrosion tests were performed in a triboelectrochemical cell containing the electrolyte $(9 \mathrm{~g} / \mathrm{L} \mathrm{NaCl})$ and electrodes (Fig. 2). Prior to the tribocorrosion tests, the untreated samples were etched in Kroll's reagent and kept in desiccator for $24 \mathrm{~h}$. For the tribocorrosion tests, the cell was installed on a pin-on-disc tribometer with the working surface area of the samples facing upwards. Zirconia pin $7 \mathrm{~mm}$ in diameter having a lower spherical end with $100 \mathrm{~mm}$ of radius was used as a counter material and it was mounted vertically above the exposed sample area $\left(1.13 \mathrm{~cm}^{2}\right)$ where it rotated clockwise over the samples. Open circuit potential (OCP) was monitored before, during and after sliding at room temperature $\left(25 \pm 1^{\circ} \mathrm{C}\right)$ using Parstat 2263 potentiostat (Princeton Applied Research). A three-electrode electrochemical cell with an electrolyte volume of $225 \mathrm{ml}$ was used, where a saturated calomel electrode (SCE) was used as the reference electrode, a Pt net was used as the counter electrode, and the samples were used as the working electrode. The OCP was considered stable when $\triangle \mathrm{E}$ was below $60 \mathrm{mV} \mathrm{h}^{-1}$ and the pin was loaded, the sliding started in a unidirectional system with track diameter of $4 \mathrm{~mm}$, frequency of $1 \mathrm{~Hz}$ (60 rpm), and total sliding time of $30 \mathrm{~min}$ (1800 cycles). The normal load was chosen as $3 \mathrm{~N}$, corresponding to maximum Hertzian contact pressure 


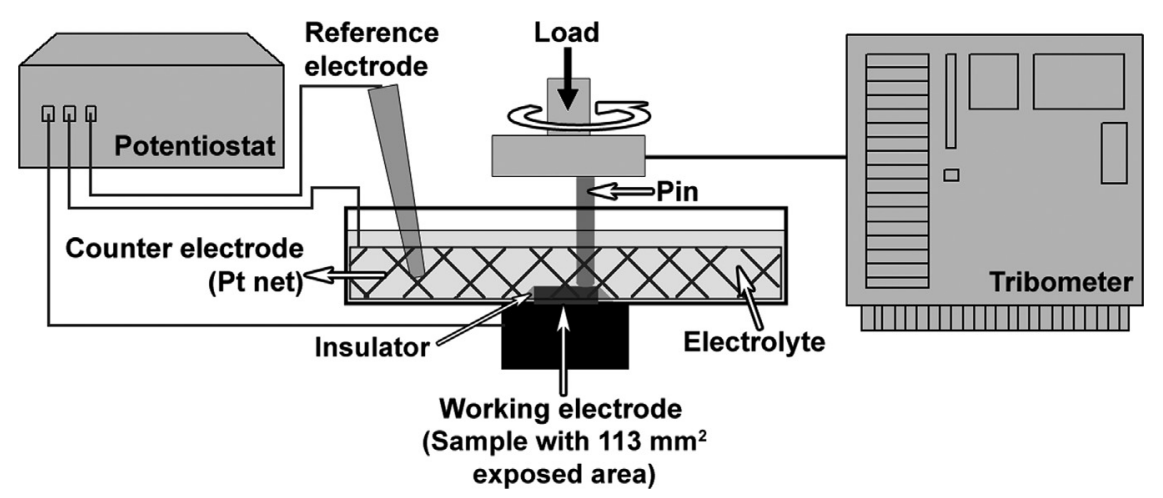

Fig. 2. Schematic representation of the tribocorrosion test setup.

of $80.8 \mathrm{MPa}$, in order to not to exceed the yield strength of dense $\mathrm{Ti}$ (typically between 275 and $410 \mathrm{MPa}$ for CP Ti grade 2 (ASM Inc, 2016)), but as well, to have significantly higher contact pressures as compared to the ones reported for the hip implants (between approx. 3 and $9 \mathrm{MPa}$ (Yoshida et al., 2006)), since it is known that the attachment of a porous material to the bone helps to distribute load over a larger area resulting in lower stress concentrations (Aly, 2010). After sliding, the pin was unloaded and the OCP values kept on monitoring during $30 \mathrm{~min}$.

\subsection{Characterization}

As-processed, as-functionalized samples and worn surfaces were characterized by using FEI Nova 200 Field Emission Gun Scanning Electron Microscopes (FEG-SEM), equipped with EDAX-Pegasus energy dispersive X-ray spectroscopy and EDAX Metek New XL30 (EDS), as well X-ray diffraction (XRD, $\mathrm{Cu}$ Ka radiation, Bruker D8 Discover). Surface topographies were examined by microtopography (TIL Microtopographe CHR 150).

Porous Ti samples were examined by micro computed tomography (micro-CT) in order to investigate the porosity percentage and porosity distribution by using X-view X 50-CT (North Star Imaging) micro-CT system. The acquisition was realized with the accelerating voltage of $50 \mathrm{KV}$ and a tube current of $400 \mu \mathrm{A} .1200$ projections were taken for each sample over $360^{\circ}\left(0.3^{\circ}\right.$ range $)$ with an exposure time of $3 \mathrm{~s}$ per projection. CMOS image sensor $(3888 \times 3072$ pixels $)$ coupled to CsI scintillator was used to detect the transmission beam. Each sample was scanned with a pixel size of $17 \mu \mathrm{m} \times 17 \mu \mathrm{m}$, yielding a field of view of about $3 \mathrm{~cm}$. Each sample acquisition generated 2400 TIFF projections, which were used in the reconstruction process resulting in volumetric data of $20.2 \mathrm{~GB}$. The average scanning time of each sample was $90 \mathrm{~min}$.

\section{Results and discussion}

\subsection{As-processed surfaces}

Three-dimensional microtomograhpic reconstructions of the porous samples are given in Fig. 3 (hereafter the porous samples will be referred as Ti22 and Ti37 due to the real porosity values previously measured by image analysis (Alves et al., 2016)). As can be seen on the images, Ti22 samples presented mainly closed pores whereas Ti37 samples exhibited combination of open (interconnected) and closed pores. 3D microtomograhpic reconstructions also revealed relatively homogeneous distribution of the pores in the three-dimensional structure. Average porosity values were also calculated from microtomograhpic reconstructions as 21 and 35\% for Ti22 and Ti37, respectively.

Secondary electron (SE) SEM images of the as-etched and asfunctionalized samples are given in Fig. 4. In order to obtain similar roughness values, dense Ti samples were grinded with 180 mesh SiC paper before etching and the grinding marks were still visible after etching (Fig. 4a). All etched surfaces exhibited residual porosity (in addition to the induced porosity on Ti22 and Ti37 samples) that is a natural consequence of the conventional powder metallurgy processing route (Alves et al., 2016; Bi et al., 2012). As it was previously discussed elsewhere (Alves et al., 2016) for the as-processed samples, the porosity was measured by image analysis as 22 and $37 \%$ for the porous samples processed by adding 30 and 50 vol.\% of urea, respectively, as a result of the shrinkage that had been reported as increased with the increasing amount of space holder (Alves et al., 2016; Laptev et al., 2004; Tuncer et al., 2011). On the other hand, 1\% of difference in porosity between the values obtained by image analysis and micro-CT can be related to the plastic deformation occurred during grinding and polishing performed before image analysis.

Anodic treated surfaces exhibited typical volcano-like porous and rough surface structure (Fig. $4 \mathrm{~d}-\mathrm{f}$ ). While as-etched samples presented average surface roughness $\left(S_{a}\right)$ of $0.63 \mu \mathrm{m}$, anodized samples presented the average values of $1.27 \mu \mathrm{m}$. As a consequence of the increased roughness, grinding marks were barely visible on the dense functionalized samples (Fig. 4d). Moreover, in addition to the outmost surfaces, inner pores were also successfully functionalized on the porous samples (Fig. 4e and f).

Ishizawa et al. (1995) were among the first authors worked on anodic treatment to produce titanium oxide films doped with bioactive elements, where a mixture of $\beta$-glycerophosphate and calcium acetate was used as the anodizing electrolyte to incorporate $\mathrm{Ca}$ and $\mathrm{P}$ in the anodic oxide film. Previous study of some of the present authors (Alves et al., 2013) reported that the amount of Ca incorporated into the oxide layers increased with increasing calcium acetate concentration in the electrolyte, resulting in $3.53 \pm 0.14 \mathrm{Ca} / \mathrm{P}$ weight ratio in the oxide film for the $0.35 \mathrm{M} \mathrm{CA}+0.02 \mathrm{M} \beta$-GP electrolyte, whereas the $\mathrm{Ca} / \mathrm{P}$ ratio had obtained as $1.57 \pm 0.14$ when the $0.15 \mathrm{M} \mathrm{CA}+0.02 \mathrm{M} \beta$-GP electrolyte had been used for the anodic treatment. However, when the CA concentration was $0.15 \mathrm{M}$, the oxide film was just composed of anatase, whereas increased concentration of CA led to formation of a mixture of anatase and rutile. It is known that such an oxide layer can improve the biological, electrochemical and triboelectrochemical properties of titanium (Alves et al., 2015). Anatase can improve the bioactivity due to its high reactivity leading to formation of bone-like apatite (Salantiu et al., 2015) whereas rutile has significantly higher hardness compared to anatase (approximately $1733 \mathrm{HV}$ and $815 \mathrm{HV}$, respectively) and presents better wear resistance (Biswas and Dutta Majumdar, 2009; Krishna et al., 2007; Dong and Bell, 2000; Yetim, 2010). Thus, an electrolyte of $0.35 \mathrm{M} \mathrm{CA}+0.02 \mathrm{M} \beta$-GP was used in the present study in order to obtain a mixture of anatase and rutile on the anodic films. As in accordance with the previous findings, $\mathrm{Ca}$ and $\mathrm{P}$ were detected on the EDS spectra taken from all anodized samples (Fig. 5a) where average $\mathrm{Ca} / \mathrm{P}$ weight ratios were measured as $3.40 \pm 0.17,3.39 \pm 0.22$, and 3.25 \pm 0.15 for the dense Ti, Ti22, and Ti37 samples, respectively. This composition of the electrolyte also led to a mixture of anatase and rutile, as can be seen on the XRD spectra given in Fig. 5b. 

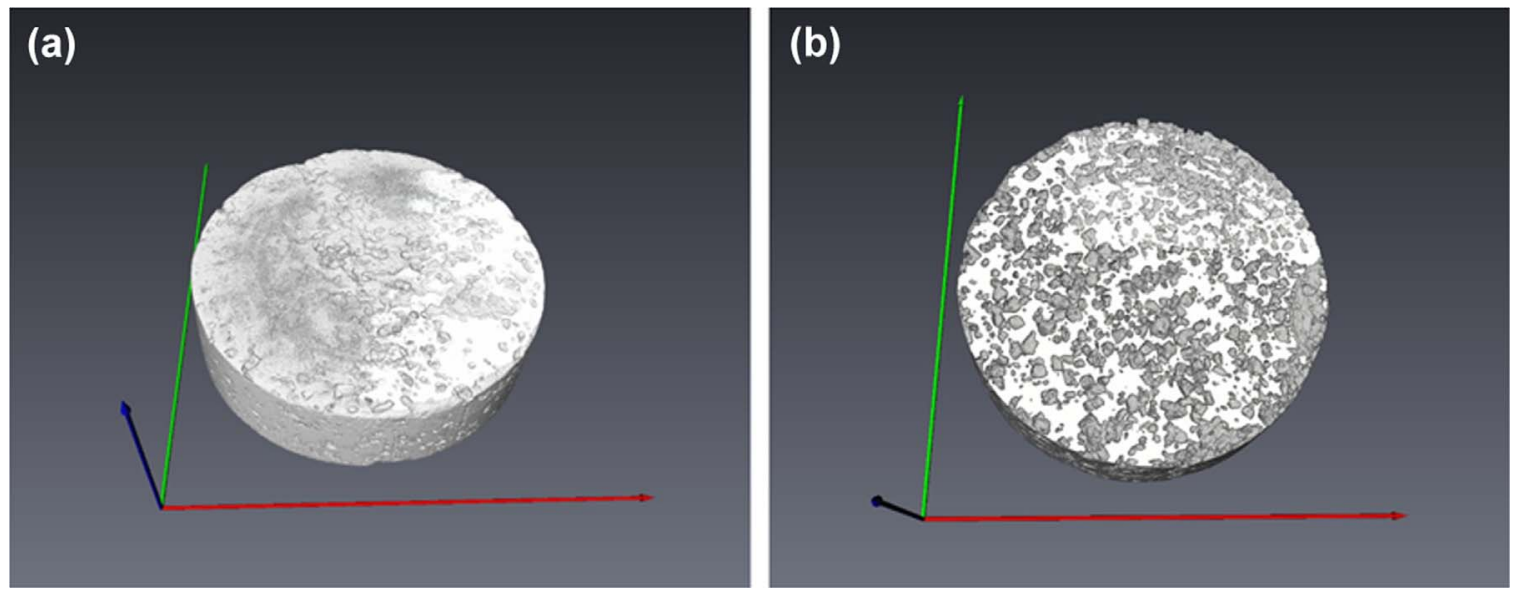

Fig. 3. Three-dimensional microtomograhpic reconstructions of a) Ti22 and b) Ti37 samples.

\subsection{Worn surfaces}

Fig. $6 \mathrm{a}-\mathrm{f}$ presents the representative lower magnification SEM images of the worn surfaces both in secondary electron (SE) and backscattered electron (BSE) modes. Untreated dense Ti samples presented well-known worn surface features for Ti, namely, parallel sliding grooves due to abrasive wear, together with compacted oxidized wear debris. While the wear tracks were well distinguishable on the dense samples (both untreated and treated), the tracks were not as clearly noticeable on the porous samples. Additionally, in all cases, functionalized samples exhibited less visible wear damage as compared to the untreated samples. On the other hand, formation of compacted wear debris or a tribolayer was more distinguishable on both untreated and treated dense worn surfaces.

Fig. $6 \mathrm{~g}-\mathrm{j}$ gives the representative EDS spectra taken from the worn sample and counter material (zirconia pin) surfaces. Presence of $\mathrm{O}$ on the untreated samples reveals the formation of the oxidative wear in all cases (Fig. 6g). On the treated samples, presence of $\mathrm{Ca}$ and $\mathrm{P}$ shows
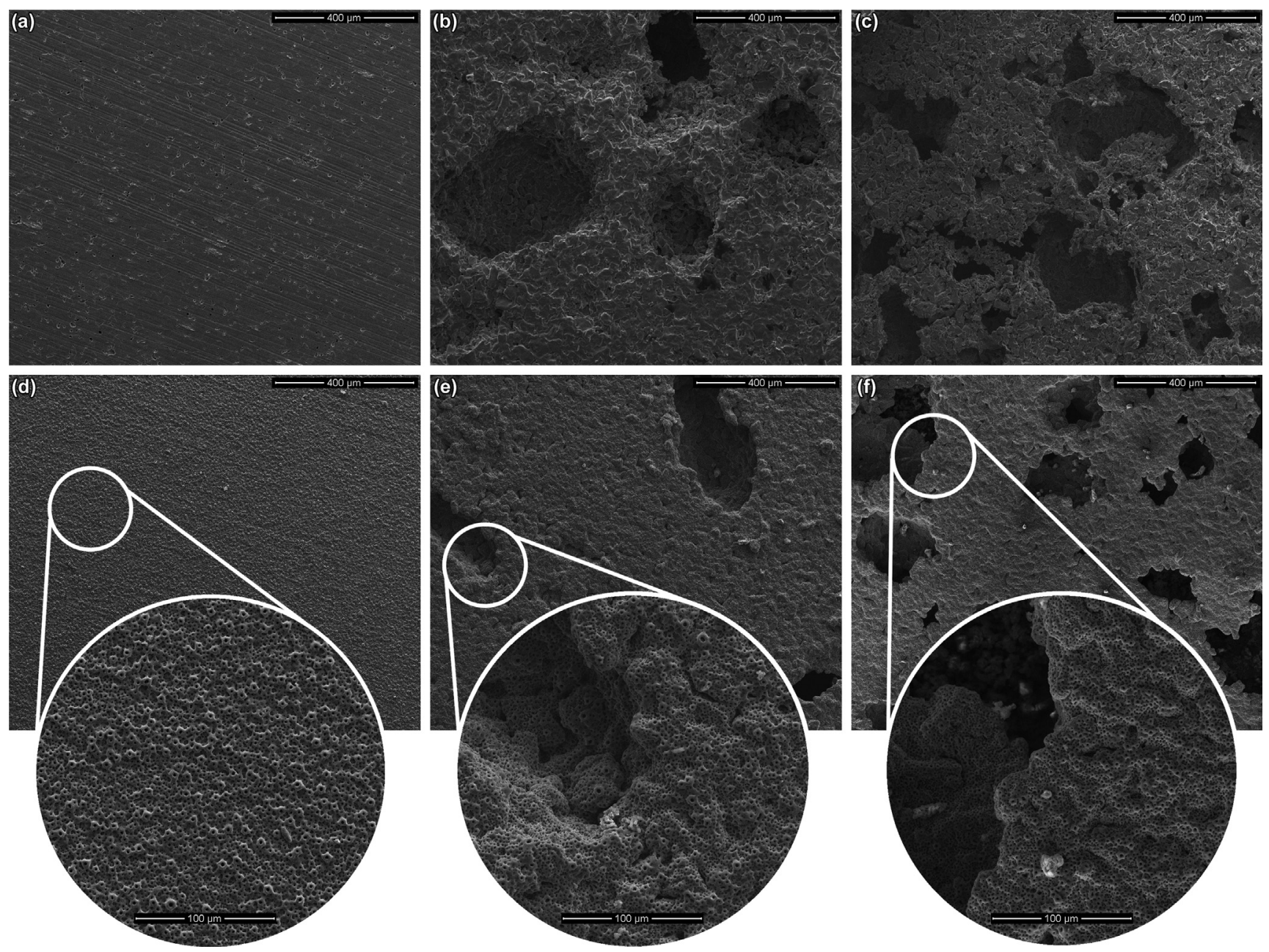

Fig. 4. Secondary electron SEM images of the as-etched (a-c) and as-functionalized (d-f) dense, Ti22, and Ti37 samples, respectively. 

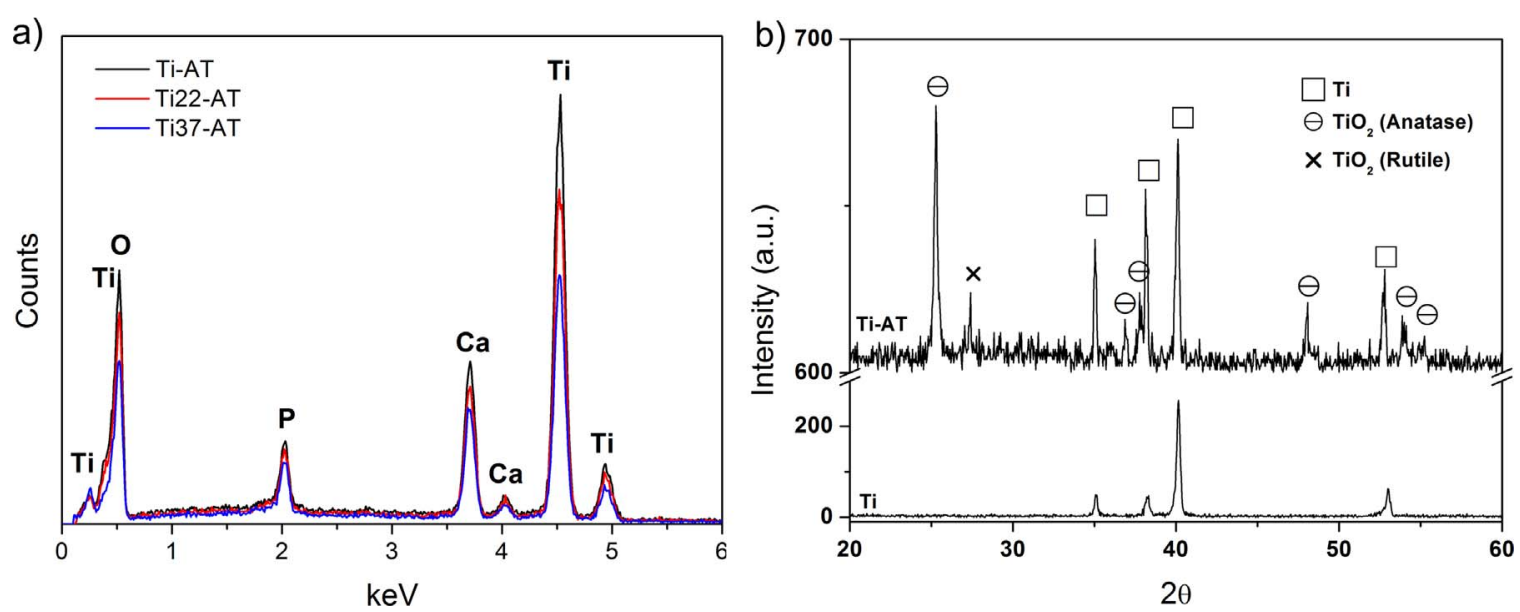

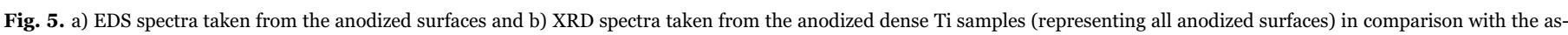
processed dense Ti.
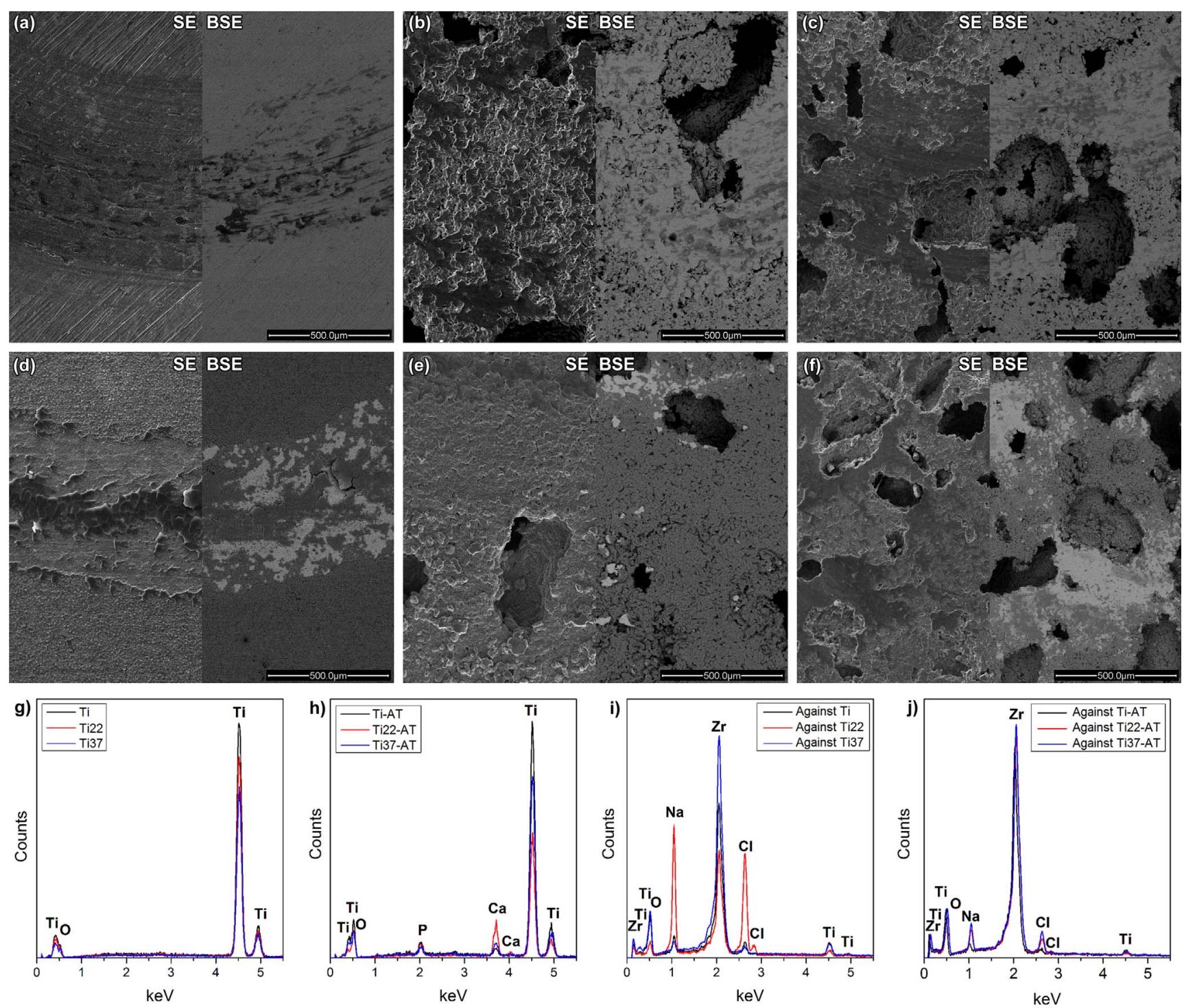

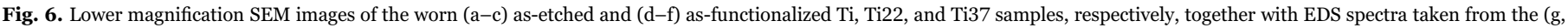
h) wear tracks and $(i, j)$ worn counter material surfaces. 

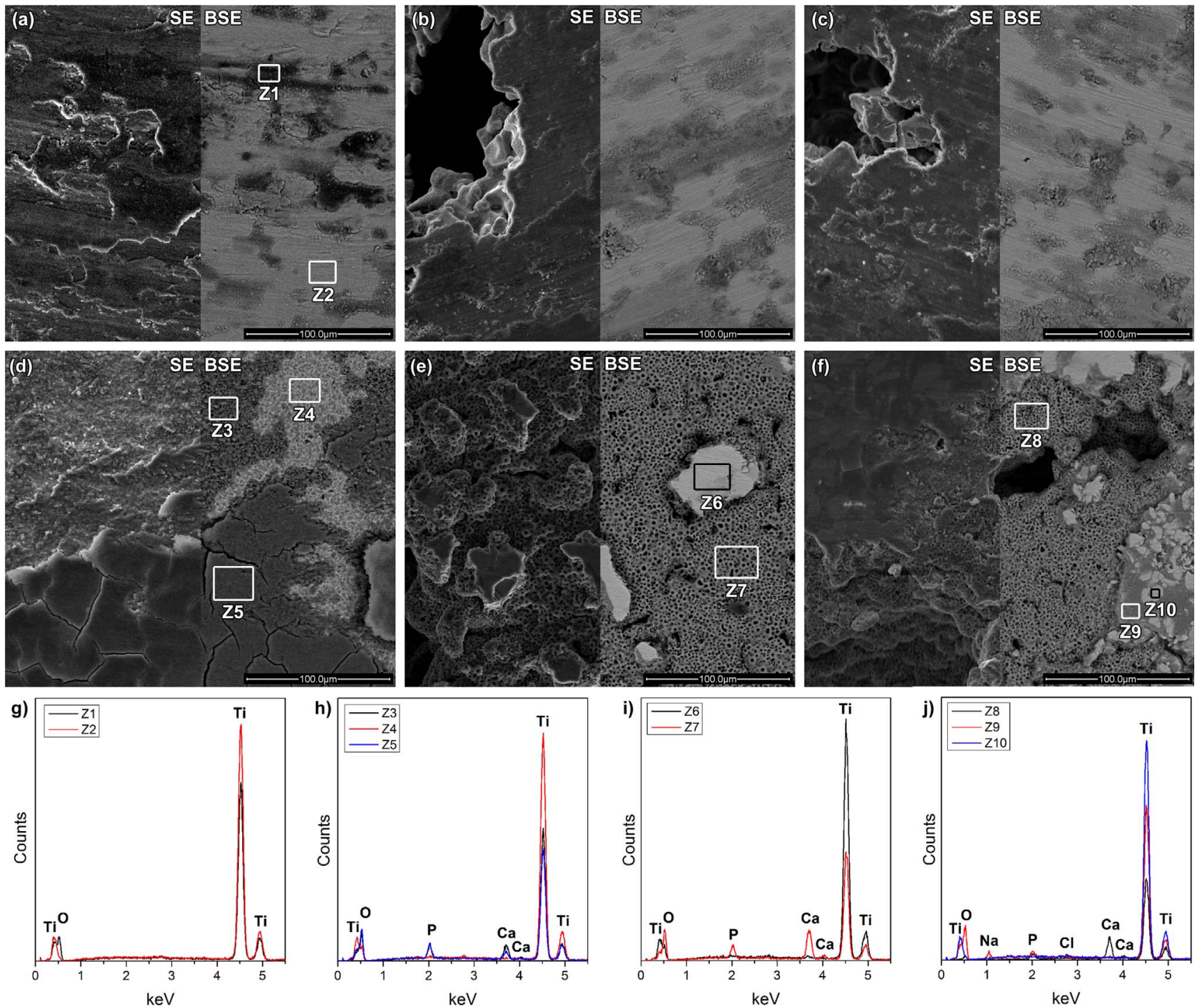

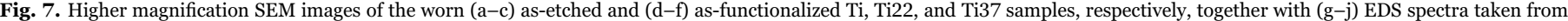
the marked zones.

that the functionalized layer was not totally removed in any of the cases (Fig. 6h). Furthermore, all pin surfaces exhibited Ti indicating the material transfer from sample surfaces to the counter material due to adhesive wear. Nevertheless, the transfer of Ti was always comparatively less for the anodic treated samples as compared to the untreated samples Fig. 6i-j.

Fig. $7 \mathbf{a}-\mathbf{j}$ presents the representative higher magnification SEM images of the worn surfaces, together with EDS spectra taken from the characteristic zones. Fig. 7a gives a closer look to the compacted oxide debris formed on the worn Ti surface, where the difference on the $\mathrm{O}$ content (Z1) as compared to the rest of the wear track (Z2) can be seen clearly (Fig. 7g). These oxides can either play a protective role by reducing the damage especially given by adhesive wear, or they can freely move on the sliding surface resulting in third-body wear (Yetim, 2010; Hibi et al., 2008). Ti22 and Ti37 samples presented similar worn surfaces (Fig. 7b and c) but the compacted oxide debris were not as intense as the Ti sample, probably due to ejecting of some of these oxide debris into the pores.

Functionalized samples presented completely different worn surfaces (Fig. $7 d-f$ ) as compared to the untreated samples. Ti-AT surfaces exhibited three distinctive zones; $\mathrm{Z3}$, contains $\mathrm{O}$, Ti, Ca, and $\mathrm{P} ; \mathrm{Z4}$, contains lower amount of $\mathrm{O}$, higher amount of Ti without $\mathrm{Ca}$ and $\mathrm{P}$; and
Z5 (tribolayer), giving a similar spectrum to Z3. Similar worn surfaces to the Ti samples had also been observed by several authors for $\mathrm{Ti}$ or Ti6Al4V alloy after modified by micro-arc oxidation or plasma electrolytic oxidation and worn in physiological fluids (Fazel et al., 2015; De Viteri et al., 2016; Vangolu et al., 2011). In a recent paper, De Viteri et al. (2016) investigated the tribocorrosion behavior of Ti6Al4V treated by plasma electrolytic oxidation with the incorporation of $\mathrm{Ca}$ and $\mathrm{P}$. The authors reported that part of the modified surfaces were removed during sliding and re-deposited to the surface resulting in a formation of a protective tribolayer. In the present work, as opposed to the Ti-AT samples, this tribolayer was not observed on the Ti22-AT and Ti37-AT samples (Fig. 7e and f), probably due to ejection of these broken oxide debris into the pores. Instead, the functionalized porous samples (Ti22-AT and Ti37-AT) exhibited mainly two distinctive regions on the worn surfaces; protruded zones that carried the load and lost the modified oxide layer (Z6, Z9, and Z10), where mainly Ti and $\mathrm{O}$ elements were detected by EDS analysis, then $\mathrm{Z} 7$ and $\mathrm{Z} 8$ zones that were not significantly disturbed by the counter material and kept its typical morphology of the anodic treatment, together with the typical composition (Fig. 7i and j). Oxidized zones were also detected on some wider protruded zones (Z9), however, the composition were different than the tribolayer formed on the Ti-AT sample (Z5). 


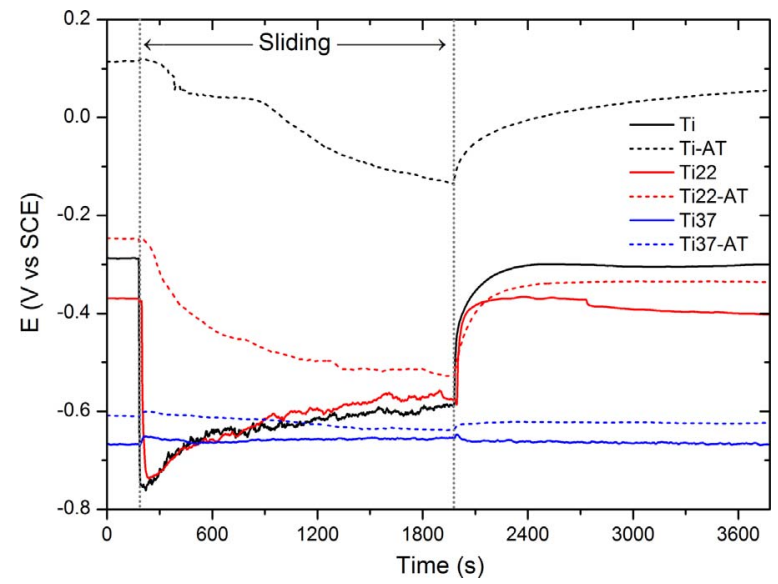

Fig. 8. Evolution of OCP before, during and after sliding.

\subsection{Evolution of $O C P$}

The Fig. 8 presents the evolution of OCP before, during, and after sliding. Before sliding, the functionalized surfaces always exhibited more positive potential values as compared to the as-etched surfaces, due to the oxide layer formed by the anodic treatment. However, the stabilization OCP values before sliding were decreased for both asetched and as-functionalized samples with the increase on porosity. This alteration may be attributed to the difference on the nature and quality of the native oxide films between the one formed on the outmost surface and on the pore surfaces. The present authors have recently been reported (Alves et al., 2016) that the heterogeneities of the oxide film formed on the pore surfaces impeded the formation of the passive plateau on the porous Ti samples. Furthermore, due to the difficulty on the electrolyte penetration through the pores as well as the difficulty on the oxygen diffusion, differences were observed on the thickness and the nature of the oxide layers between the samples. Eventually, porous samples exhibited higher $i_{\text {corr }}$ values as compared to the dense samples. Accordingly, as one may expect, the differences on the anodic films formed on the outmost surface and the pore surfaces (as well, the inner pore surfaces) may also create difference observed on the dense and porous functionalized samples.

When sliding started, a sudden decrease on OCP values was observed for Ti samples due to the mechanical damage on the passive film, leading to the formation of the active sites on the worn surfaces, that is the typical behavior of the passive metals under sliding solicitations (Diomidis et al., 2012; Toptan et al., 2016; Fernandes et al., 2006; Galliano et al., 2001). During sliding, the OCP values were gradually increased that can be attributed to the limited protective role given by the compacted oxide debris (Mathew et al., 2008; Ribeiro et al., 2015; Toptan et al., 2013).

After sliding, the OCP values were rapidly increased and stabilized near the initial values due to recovery of the passive film (Diomidis et al., 2012; Toptan et al., 2016). Under sliding, Ti22 samples presented very similar behavior to the Ti samples, however, Ti37 samples exhibited a totally different behavior, where OCP values were not significantly influenced by sliding. It is known that OCP values obtained during sliding are mixed potential values, reflecting both the active (worn) and passive (unworn) surfaces (Diomidis et al., 2012; Fernandes et al., 2006). Moreover, as Bayón et al. (2010) reported, not only the outside of the wear track, but as well the pore surfaces under the wear track should also be considered as the unworn area. In addition to the increased pore area (i.e. decreased disturbed metallic surface by rubbing), accumulation of the oxide wear debris into the pores could decrease the effect of the third-body wear, which is another factor that gives a damage to the passive film (Ribeiro et al., 2015; Yan et al., 2009). As a result, the behavior of Ti37 samples may be explained by the combination of all these factors, together with considering the less protective nature of the oxide film formed on the pore, and inner pore surfaces (Alves et al., 2016).

Similar to the stabilization values, as compared to the as-etched surfaces, functionalized surfaces presented more positive OCP values during and after sliding where the most positive OCP values were obtained from the Ti-AT samples. When sliding started, instead of presenting a sharp drop on potentials such as Ti samples, a delayed and relatively slow initial drop was observed. After that, the values were kept almost constant between approx. first 200 and $675 \mathrm{~s}$ of sliding. Following this plateau, the values were gradually decreased till the end of the sliding. The delayed drop on the Ti-AT samples can be attributed to the increased wear resistance given by the anodic oxide layer. The plateau observed after the initial potential drop may be explained by the formation of the tribolayer that seemed to play a protective role against corrosion and wear. However, after a certain time, this layer may get thicker and cracked, then cracked oxide debris (i.e. third-body particles) may result in a gradual decrease on the potential values after provoking a third-body abrasion. Similar behavior had also been observed by Alves et al. (2013) for anodized Ti. Apart from the more negative OCP values, Ti22-AT samples presented very similar behavior to the Ti-AT samples, except for the potential plateau observed on Ti-AT samples under sliding. This difference can be attributed to the tribolayer which was not so evident on Ti22-AT samples probably due to ejection of the oxide wear debris into the pores. On the other hand, Ti37-AT samples presented similar behavior to the untreated ones, except for a small positive shift on the overall potential values. Additionally, as it stated above, the load was mainly carried by the protruded surfaces on the porous functionalized samples (Fig. 7e and f) which resulted in a reduced disturbed surface area that is also another contribution on the more positive OCP values obtained under sliding, as compared to the as-etched samples.

As oppose to the as-etched samples, after sliding, the OCP values were stabilized at relatively lower values for all functionalized samples, as compared to the initial values, suggesting a permanent damage on the anodic oxide layer, as it had also been reported in the literature for the anodized dense surfaces (Alves et al., 2013; Fazel et al., 2015; De Viteri et al., 2016; da et al., 2016). Even though, the stabilization values after sliding were always much higher as compared to the ones recorded for the as-etched samples.

In the present work, since six different and complex surfaces were studied, as a first approach, measurement of corrosion potential is chosen as the triboelectrochemical technique. On the other hand, as the major compound of the physiological body fluids, $9 \mathrm{~g} / \mathrm{L}$ of $\mathrm{NaCl}$ was used as an electrolyte in order to avoid the complexity of the physiological body fluids. Obviously, in order to have a better understanding to the tribocorrosion behavior of these functionalized highly porous surfaces, tribocorrosion tests should also be studied as a function of critical tribological parameters, especially normal load and sliding distance. Synergism between corrosion and wear should be evaluated, together with the quantification of wear loss and metallic ion releasing. Furthermore, the effect of proteins and bio-organisms to the triboelectrochemical and frictional behavior also needs to be evaluated. On the other hand, in addition to sliding tribocorrosion, fretting corrosion should also be studied owing to its importance on the bone/implant interface. Finally, detailed mechanical characterization, as well as the in vitro and in vivo biological phenomena and mechanisms should be understood.

\section{Conclusions}

Tribocorrosion behavior of porous Ti having closed and interconnected pores with the average porosities of 22 and 37\% was investigated in $9 \mathrm{~g} / \mathrm{L} \mathrm{NaCl}$ solution against zirconia pins. Results suggested that all bio-functionalized samples presented higher OCP values before, during and after sliding, indicating lower tendency to corrosion, not 
just due to the improved corrosion resistance by the oxide layers formed on the outmost surface and pore surfaces, but also due to its high hardness and therefore high resistance to wear. As a result, during tribocorrosion action, the counter material mainly slid over the protruded anodized surfaces resulting in less mechanical damage on the functionalized surfaces. Moreover, ejection of the wear debris into the pores decreased the third-body abrasion that also contributed to the improved tribocorrosion performance. However, further studies are needed in order to have a deeper understanding to the tribocorrosion behavior of porous $\mathrm{Ti}$, namely potentiostatic tribocorrosion tests for understanding the corrosion kinetics under sliding, as well, fretting corrosion tests in order to simulate better the bone/implant interface.

\section{Acknowledgments}

This study was supported by FCT with the reference project UID/ EEA/04436/2013, by FEDER funds through the COMPETE 2020 Programa Operacional Competitividade e Internacionalização (POCI) with the reference project POCI-01-0145-FEDER-006941, Programa de Acções Universitárias Integradas Luso-Francesas' (PAUILF TC12_14), and the Calouste Gulbenkian Foundation through "Programa de Mobilidade Académica para Professores". The authors also gratefully acknowledge the "Investissements d'avenir" programs (nos. ANR11-IDEX-0003-02 and ANR-10- EQPX-37 MATMECA Grant) for financial support.

\section{References}

Alves, A.C., Oliveira, F., Wenger, F., Ponthiaux, P., Celis, J.-P., Rocha, L.A., 2013. Tribocorrosion behaviour of anodic treated titanium surfaces intended for dental implants. J. Phys. D Appl. Phys. 46, 404001.

Alves, A.C., Sendão, I., Ariza, E., Toptan, F., Ponthiaux, P., Pinto, A.M.P., 2016. Corrosion behaviour of porous Ti intended for biomedical applications. J Porous Mater. 23, 1261-1268.

Alves, S.A., Bayón, R., de Viteri, V.S., Garcia, M.P., Igartua, A., Fernandes, M.H., et al., 2015. Tribocorrosion behavior of calcium- and phosphorous-enriched titanium oxide films and study of osteoblast interactions for dental implants. J. Biol. Tribol. Corros. $1,23$.

Aly, M.S., 2010. Effect of pore size on the tensile behavior of open-cell Ti foams: experimental results. Mater. Lett. 64, 935-937.

Amin Yavari, S., Ahmadi, S.M., van der Stok, J., Wauthle, R., Riemslag, A.C., Janssen, M., et al., 2014. Effects of bio-functionalizing surface treatments on the mechanical behavior of open porous titanium biomaterials. J. Mech. Behav. Biomed. Mater. 36, $109-119$.

ASM Inc. Webpage, 2016. 〈http://asm.matweb.com/search/SpecificMaterial.asp? Bassnum=MTP641 $>$.

Bayón, R., Nevshupa, R., Zubizarreta, C., Ruiz, U., de Gopegui, Barriga, J., Igartua, A., 2010. Characterisation of tribocorrosion behaviour of multilayer PVD coatings. Anal. Bioanal. Chem. 396, 2855-2862.

Benea, L., Mardare-Danaila, E., Mardare, M., Celis, J.-P., 2014. Preparation of titanium oxide and hydroxyapatite on Ti-6Al-4V alloy surface and electrochemical behaviour in bio-simulated fluid solution. Corros. Sci. 80, 331-338.

Bi, H.L., Yu, C.Z., Cao, P., He, Y.H., 2012. Porous Ti-6Al-4V alloy prepared by a pressand-sinter process. Key Eng. Mater. 520, 76-81.

Biswas, A., Dutta Majumdar, J., 2009. Surface characterization and mechanical property evaluation of thermally oxidized Ti-6Al-4V. Mater. Charact. 60, 513-518.

Chen, X.-B., Li, Y.-C., Du Plessis, J., Hodgson, P.D., Wen, C., 2009. Influence of calcium ion deposition on apatite-inducing ability of porous titanium for biomedical applications. Acta Biomater. 5, 1808-1820.

Correa, D.R.N., Kuroda, P.A.B., Grandini, C.R., 2014. Structure, microstructure, and selected mechanical properties of Ti-Zr-Mo alloys for biomedical applications. Adv. Mater. Res. 922, 75-80.

De Viteri, V.S., Fuentes, E., 2013. Titanium and titanium alloys as biomaterials. In: Gegner, J. (Ed.), Tribol. Fundam. Adv.. InTech.

De Viteri, V.S., Bayón, R., Igartua, A., Barandika, G., Moreno, J.E., Peremarch, C.P. et al., 2016. Structure, tribocorrosion and biocide characterization of Ca, P and I containing TiO2 coatings developed by plasma electrolytic oxidation. Appl. Surf. Sci. $367,1-10$.

Diomidis, N., Mischler, S., More, N.S., Roy, M., 2012. Tribo-electrochemical characterization of metallic biomaterials for total joint replacement. Acta Biomater. 8, 852-859.

Dong, H., Bell, T., 2000. Enhanced wear resistance of titanium surfaces by a new thermal oxidation treatment. Wear 238, 131-137.

Fan, X., Feng, B., Weng, J., Wang, J., Lu, X., 2011. Processing and properties of porous titanium with high porosity coated by bioactive titania nanotubes. Mater. Lett. 65, 2899-2901.

Fazel, M., Salimijazi, H.R., Golozar, M.A., Jazi, M.R. Garsivaz, 2015. A comparison of corrosion, tribocorrosion and electrochemical impedance properties of pure Ti and Ti6Al4V alloy treated by micro-arc oxidation process. Appl. Surf. Sci. 324, 751-756. Fernandes, A.C., Vaz, F., Ariza, E., Rocha, L.A., Ribeiro, A.R.L., Vieira, A.C., et al., 2006. Tribocorrosion behaviour of plasma nitrided and plasma nitrided+oxidised Ti6Al4V alloy. Surf. Coat. Technol. 200, 6218-6224.

Galliano, F., Galvanetto, E., Mischler, S., Landolt, D., 2001. Tribocorrosion behavior of plasma nitrided Ti-6Al-4V alloy in neutral NaCl solution. Surf. Coat. Technol. 145, $121-131$.

Ganesh, B.K.C., Ramanaih, N., Chandrasekhar Rao, P.V., 2012. Dry sliding wear behavior of Ti-6Al-4V implant alloy subjected to various surface treatments. Trans. Indian Inst. Met. 65, 425-434.

Goriainov, V., Cook, R., Latham, J.M., Dunlop, D.G., Oreffo, R.O.C., 2014. Bone and metal: an orthopaedic perspective on osseointegration of metals. Acta Biomater. 10 $4043-4057$.

Gosavi, S., Gosavi, S., Alla, R., Titanium, 2013. A MIracle Metal in Dentistry. Trends Biomater. Artif. Organs 27, 42-46.

Guo, Y., Georgarakis, K., Yokoyama, Y., Yavari, A.R., 2013. On the mechanical properties of TiNb based alloys. J. Alloy. Compd. 571, 25-30.

Hamid, A.A., Ghosh, P.K., Jain, S.C., Ray, S., 2008. The influence of porosity and particles content on dry sliding wear of cast in situ $\mathrm{Al}(\mathrm{Ti})-\mathrm{Al} 2 \mathrm{O} 3(\mathrm{TiO} 2)$ composite. Wear 265, 14-26.

Hibi, Y., Murakami, T., Miyake, K., Sasaki, S., 2008. Influence of microstructure on the wear behavior of sic-reinforced titanium-matrix composites lubricated by water and by ethanol. J. Am. Ceram. Soc. 91, 508-513.

Hu, R.-H., Lim, J.-K., 2010. Hardness and wear resistance improvement of surface composite layer on Ti-6Al-4V substrate fabricated by powder sintering. Mater. Des. 31, 2670-2675.

Hu, X., Shen, H., Shuai, K., Zhang, E., Bai, Y., Cheng, Y., et al., 2011. Surface bioactivity modification of titanium by $\mathrm{CO} 2$ plasma treatment and induction of hydroxyapatite: in vitro and in vivo studies. Appl. Surf. Sci. 257, 1813-1823.

Ishizawa, H., Ogino, M., 1995. Characterization of thin hydroxyapatite layers formed on anodic titanium oxide films containing $\mathrm{Ca}$ and $\mathrm{P}$ by hydrothermal treatment. J. Biomed. Mater. Res. 29, 1071-1079.

Ishizawa, H., Fujino, M., Ogino, M., 1995. Mechanical and histological investigation of hydrothermally treated and untreated anodic titanium oxide films containing Ca and P. J. Biomed. Mater. Res. 29, 1459-1468.

Jha, N., Badkul, A., Mondal, D.P., Das, S., Singh, M., 2011. Sliding wear behaviour of aluminum syntactic foam: a comparison with $\mathrm{Al}-10 \mathrm{wt} \% \mathrm{SiC}$ composites. Tribol. Int. 44, 220-231.

Jha, N., Mondal, D.P., Dutta Majumdar, J., Badkul, A., Jha, A.K., Khare, A.K., 2013. Highly porous open cell Ti-foam using $\mathrm{NaCl}$ as temporary space holder through powder metallurgy route. Mater. Des. 47, 810-819.

Krishna, D. Siva Rama, Brama, Y.L., Sun, Y., 2007. Thick rutile layer on titanium for tribological applications. Tribol. Int. 40, 329-334.

Landolt, D., Mischler, S., Stemp, M., Barril, S., 2004. Third body effects and material fluxes in tribocorrosion systems involving a sliding contact. Wear 256, 517-524.

Laptev, A., Bram, M., Buchkremer, H.P., Stöver, D., 2004. Study of production route for titanium parts combining very high porosity and complex shape. Powder Metall. 47, 85-92.

Lee, B., Lee, T., Lee, Y., Lee, D.J., Jeong, J., Yuh, J., et al., 2014. Space-holder effect on designing pore structure and determining mechanical properties in porous titanium. Mater. Des. 57, 712-718.

Lee, W.-T., Koak, J.-Y., Lim, Y.-J., Kim, S.-K., Kwon, H.-B., Kim, M.-J., 2012. Stress shielding and fatigue limits of poly-ether-ether-ketone dental implants. J. Biomed. Mater. Res. B Appl. Biomater. 100, 1044-1052.

Li, Y.-H., Rao, G.-B., Rong, L.-J., Li, Y.-Y., 2002. The influence of porosity on corrosion characteristics of porous NiTi alloy in simulated body fluid. Mater. Lett. 57, 448-451.

Marino, C.E.B., Mascaro, L.H., 2004. EIS characterization of a Ti-dental implant in artificial saliva media: dissolution process of the oxide barrier. J. Electroanal. Chem. $568,115-120$.

Marques, I. da S.V., Alfaro, M.F., da Cruz, N.C., Mesquita, M.F., Sukotjo, C., Mathew M.T., et al., 2016. Tribocorrosion behavior of biofunctional titanium oxide films produced by micro-arc oxidation: synergism and mechanisms. J. Mech. Behav. Biomed. Mater. 60, 8-21.

Martins, J.R.S., Grandini, C.R., 2014. The influence of heat treatment on the structure and microstructure of Ti-15Mo-xNb system alloys for biomedical applications. Mater. Sci. Forum 783-786, 1255-1260.

Mathew, M.T., Ariza, E., Rocha, L.A., Fernandes, A.C., Vaz, F., 2008. TiCxOy thin films for decorative applications: tribocorrosion mechanisms and synergism. Tribol. Int. 41, 603-615.

Menini, R., Dion, M.-J., So, S.K.V., Gauthier, M., Lefebvre, L.-P., 2006. Surface and corrosion electrochemical characterization of titanium foams for implant applications. J. Electrochem. Soc. 153, B13.

Mischler, S., 2008. Triboelectrochemical techniques and interpretation methods in tribocorrosion: a comparative evaluation. Tribol. Int. 41, 573-583.

Mondal, D.P., Das, S., Jha, N., 2009. Dry sliding wear behaviour of aluminum syntactic foam. Mater. Des. 30, 2563-2568.

Nag, S., Banerjee, R., 2012. Fundamentals of medical implant materials. In: Narayan, R. (Ed.), ASM Handbook, Vol. 23.

Ribeiro, A.M., Alves, A.C., Rocha, L.A., Silva, F.S., Toptan, F., 2015. Synergism between corrosion and wear on CoCrMo-Al2O3 biocomposites in a physiological solution. Tribol. Int. 91, 198-205.

Salahinejad, E., Amini, R., Marasi, M., Hadianfard, M.J., 2010. Microstructure and wear behavior of a porous nanocrystalline nickel-free austenitic stainless steel developed by powder metallurgy. Mater. Des. 31, 2259-2263. 
Salantiu, A.-M., Fekete, C., Muresan, L., Pascuta, P., Popa, F., Popa, C., 2015. Anodic oxidation of PM porous titanium for increasing the corrosion resistance of endosseous implants. Mater. Chem. Phys. 149-150, 453-459.

Seah, K.H.W., Chen, X., 1993. A comparison between the corrosion characteristics of 316 stainless steel, solid titanium and porous titanium. Corros. Sci. 34, 1841-1851.

Seah, K.H.W., Thampuran, R., Teoh, S.H., 1998. The influence of pore morphology on corrosion. Corros. Sci. 40, 547-556.

Szesz, E.M., Pereira, B.L., Kuromoto, N.K., Marino, C.E.B., de Souza, G.B., Soares, P., 2013. Electrochemical and morphological analyses on the titanium surface modified by shot blasting and anodic oxidation processes. Thin Solid Films 528, 163-166.

Tanigawa, H., Asoh, H., Ohno, T., Kubota, M., Ono, S., 2013. Electrochemical corrosion and bioactivity of titanium-hydroxyapatite composites prepared by spark plasma sintering. Corros. Sci. 70, 212-220.

Teixeira, M., Alves, A.C., Silva, F.S., Pinto, A.M., Toptan, F, 2015. Microstructural characterization of biofunctionalized titanium foams. Microsc. Microanal. 21, 55-56.

Thomann, U.I., Uggowitzer, P.J., 2000. Wear-corrosion behavior of biocompatible austenitic stainless steels. Wear 239, 48-58.

Toptan, F., Rego, A., Alves, A.C., Guedes, A., 2016. Corrosion and tribocorrosion behavior of Ti-B4C composite intended for orthopaedic implants. J. Mech. Behav. Biomed. Mater. 61, 152-163.

Toptan, F., Alves, A.C., Kerti, I., Ariza, E., Rocha, L.A., 2013. Corrosion and tribocorrosion behaviour of $\mathrm{Al}-\mathrm{Si}-\mathrm{Cu}-\mathrm{Mg}$ alloy and its composites reinforced with
B4C particles in 0.05M NaCl solution. Wear 306, 27-35.

Tuncer, N., Arslan, G., Maire, E., Salvo, L., 2011. Investigation of spacer size effect on architecture and mechanical properties of porous titanium. Mater. Sci. Eng. A 530, 633-642.

Vangolu, Y., Alsaran, A., Yildirim, O.S., 2011. Wear properties of micro arc oxidized and hydrothermally treated Ti6Al4V alloy in simulated body fluid. Wear 271, $2322-2327$.

Wood, R.J.K., 2007. Tribo-corrosion of coatings: a review. J. Phys. D Appl. Phys. 40, $5502-5521$

Xie, F.X., He, X.B., Cao, S.L., Lu, X., Qu, X.H., 2013. Structural characterization and electrochemical behaviour of a laser-sintered porous Ti-10Mo alloy. Corros. Sci. 67, 217-224.

Yan, Y., Neville, A., Dowson, D., Williams, S., Fisher, J., 2009. Effect of metallic nanoparticles on the biotribocorrosion behaviour of metal-on-metal hip prostheses. Wear 267, 683-688.

Yetim, A.F., 2010. Investigation of wear behavior of titanium oxide films, produced by anodic oxidation, on commercially pure titanium in vacuum conditions. Surf. Coat. Technol. 205, 1757-1763.

Yoshida, H., Faust, A., Wilckens, J., Kitagawa, M., Fetto, J., Chao, E.Y.S., 2006. Threedimensional dynamic hip contact area and pressure distribution during activities of daily living. J. Biomech. 39, 1996-2004. 